\title{
Effect of an action plan with ongoing support by a case manager on exacerbation-related outcome in patients with COPD: a multicentre randomised controlled trial
}

\author{
Jaap C A Trappenburg, ${ }^{1}$ Evelyn M Monninkhof, ${ }^{1}$ Jean Bourbeau, ${ }^{2}$ \\ Thierry Troosters, ${ }^{3,4,5}$ Augustinus J P Schrijvers, ${ }^{1}$ Theo J M Verheij, ${ }^{1}$ \\ Jan-Willem J Lammers ${ }^{6}$
}

\section{See Editorial, p 935}

- Additional materials are published online only. To view these files please visit the journal online (http://thorax.bmj. com)

${ }^{1}$ Julius Center for Health Sciences and Primary Care, University Medical Center Utrecht, Utrecht, The Netherlands

${ }^{2}$ Respiratory Epidemiology and Clinical Research Unit, Montreal Chest Institute, McGill University Health Center, McGill University, Montreal, Canada ${ }^{3}$ Respiratory Rehabilitation and Respiratory Division, University Hospital Leuven, Leuven, Belgium

${ }^{4}$ Department of Rehabilitation Sciences, Faculty of Physical Education and Physiotherapy, Katholieke Universiteit Leuven, Leuven, Belgium

${ }^{5}$ Respiratory Rehabilitation, UZ Gasthuisberg, Leuven, Belgium ${ }^{6}$ Department of Respiratory Medicine, University Medical Center Utrecht, Utrecht, The Netherlands

\section{Correspondence to}

Dr Jaap C A Trappenburg, Julius Center for Health Sciences and Primary Care, University Medical Center Utrecht, Heidelberglaan 100, 3584 CX Utrecht, The Netherlands; j.c.a.

trappenburg@umcutrecht.nl

TJMV and J-WJL contributed equally to this work.

Received 10 March 2011 Accepted 17 June 2011 Published Online First 23 July 2011

\begin{abstract}
Background An individualised action plan (AP) is a potentially effective method of helping patients with chronic obstructive pulmonary disease (COPD) to recognise and anticipate early exacerbation symptoms. This multicentre randomised controlled trial evaluates the hypothesis that individualised APs reduce exacerbation recovery time.
\end{abstract}

Methods Two hundred and thirty-three patients with COPD lage $65 \pm 10$ years, forced expiratory volume in $1 \mathrm{~s}$ $56 \pm 21 \%$ predicted) were randomised to receive either an individualised AP ( $n=111)$ or care as usual $(n=122)$. The AP provides individualised treatment prescriptions (pharmaceutical and non-pharmaceutical) related to a colour-coded symptom status to enhance an adequate response to periods of symptom deterioration (reinforced at 1 and 4 months). Exacerbation onset was defined using the Anthonisen symptom diary card algorithm. Every 3 days the Clinical COPD Questionnaire (CCO) was assessed to evaluate the longitudinal course of health status. The primary outcome was health status recovery in the event of an exacerbation.

Results During the 6-month follow-up period there was no difference in exacerbation rates and healthcare utilisation between the two groups. Cox-adjusted survival analysis including frailty showed enhanced health status recovery (HR 1.58; $95 \% \mathrm{Cl} 0.96$ to 2.60 ) and reduced length of the exacerbation ( $\mathrm{HR} \mathrm{1.30;95 \%} \mathrm{Cl} 0.92$ to 1.84). The mean difference in symptom recovery time was -3.68 days $(95 \% \mathrm{Cl}-7.32$ to -0.04$)$. Mixed model repeated measure analysis showed that an AP decreased the impact of exacerbations on health status both in the prodromal and early post-onset periods. Between-group differences in CCO scores were above the minimal clinically relevant difference of 0.4 points ( $3.0 \pm 0.7$ vs $3.4 \pm 0.9 ; p \leq 0.01$ ).

Conclusion This study shows that an individualised AP, including ongoing support by a case manager, decreases the impact of exacerbations on health status and tends to accelerate recovery. APs can be considered a key component of self-management programmes in patients with COPD.

\section{INTRODUCTION}

Chronic obstructive pulmonary disease (COPD) is a major cause of morbidity and death worldwide. ${ }^{1}$ Its stable state is punctuated by periods of worsening symptoms which vary in severity and

\section{Key messages}

What is the key question?

- We hypothesized that in the event of an exacerbation, an Action Plan aiming at early contact of healthcare providers and thus prompt intervention, leads to faster recovery in symptoms and health status.

\section{What is the bottom line?}

- This study showed that individualized written Action Plans including ongoing support of a case manager; 1) decreased the impact of exacerbations on health status, 2) decreased symptom intensity of exacerbations, and 3) tends to accelerate recovery of exacerbations in terms of health status and symptoms.

\section{Why read on?}

- This multicentre randomized controlled trial evaluates the effectiveness of a simple and straightforward intervention to decrease the impact of COPD exacerbations.

frequency, both during the course of a patient's illness and between patients. These periods are referred to as exacerbations. Exacerbations may enhance disease progression by accelerating the decline in lung function, ${ }^{2}{ }^{3}$ exercise tolerance ${ }^{4}$ and quality of life. ${ }^{5}{ }^{6}$ Furthermore, adjusted for disease severity, patients with exacerbations have higher mortality rates than patients without exacerbations. $^{78}$

Not all exacerbations are captured by healthcare contacts. Although most patients with COPD report being able to recognise the early warning signs of an exacerbation, ${ }^{9}$ previous studies have shown that $<50 \%$ of exacerbations will not be reported to the healthcare providers and subsequently do not receive the correct treatment. ${ }^{10-12}$ Although unreported exacerbations tend to be milder, they have been shown to impact adversely on the patient's health over the intermediate and long term and therefore cannot be disregarded..$^{10} 13$ Moreover, patients who habitually delay or fail to seek treatment for their exacerbations or have a lower self-management capacity have been 
shown to have slower recovery from exacerbations, worse quality of life and are more likely to be hospitalised. ${ }^{14} 15$ This underlines the importance of improving self-management skills to enhance early detection and to take early and appropriate actions by patients in exacerbation episodes.

A potentially effective method of helping patients to recognise and anticipate the early symptoms of an exacerbation is a socalled 'action plan' (AP). Multi-component self-management programmes including case management have been shown to improve patient outcomes and to reduce health service utilisation. ${ }^{16}$ However, a simplified approach such as a written AP with limited education has been shown to increase patients' selfmanagement strategies for exacerbations, but effectiveness has not been shown in clinical COPD outcome parameters. ${ }^{17}$

We designed a multicentre randomised controlled trial to evaluate the effectiveness of a simplified approach including a written AP with ongoing support by a nurse case manager in addition to care as usual in patients with COPD. We hypothesised that, in the event of an exacerbation, an AP aiming at early contact with healthcare providers and therefore prompt intervention would lead to faster recovery in symptoms and health status.

\section{METHODS}

The study was conducted as a multicentre randomised controlled trial with a 6-month follow-up period, as previously described in detail elsewhere. ${ }^{18}$ Patients were randomly assigned to either care as usual or treatment with an individualised AP in addition to care as usual. The modified informed consent procedure (postponed information) meant that patients were unaware of the major aim of the study, thereby enabling a single-blind study design. ${ }^{18}$ This procedure was approved by the medical ethical committee of the University Medical Center Utrecht since the intervention entailed no risk. ${ }^{19}$ To conceal the assignment sequence, a central web-based service was used. Randomisation was carried out using the minimisation technique to balance the control and intervention groups for centre and gender.

Patients were recruited at scheduled visits to a respiratory nurse in eight regional hospitals and five general practices. ${ }^{18}$ Eligible candidates were informed 2 weeks before a scheduled (regular) visit to the respiratory nurse (figure 1). Patients were selected based on the following inclusion criteria: (1) postbronchodilator ratio of forced expiratory volume in $1 \mathrm{~s}$ to forced vital capacity $\left(\mathrm{FEV}_{1} / \mathrm{FVC}\right)<70 \%$; (2) age $>40$ years; (3) smoking

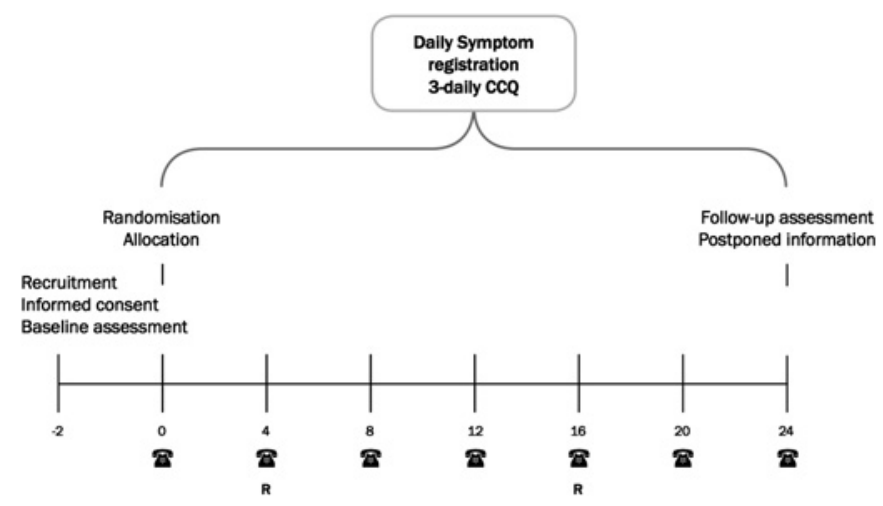

Figure 1 Schematic overview of the study procedure. Patients were recruited and informed, 2 weeks before randomisation. CCO, Clinical COPD Questionnaire; $\mathrm{R}$, reinforcement of action plan only for the intervention group. history of $>20$ years or 15 pack-years; (4) diagnosis of COPD as a major functionally limiting disease; and (5) current use of bronchodilator therapy. Exclusion criteria were: (1) primary diagnosis of asthma; (2) primary diagnosis of cardiac disease; and (3) presence of disease that could either affect mortality or participation in the study (eg, confusional states). ${ }^{18}$

Patients in both study arms received usual care, which included pharmacological and non-pharmacological care according to most recent evidence-based guidelines. ${ }^{20}$ At inclusion all patients were seen by the nurse case manager (respiratory nurse) who systematically checked and discussed the following aspects of COPD care: vaccination, optimising medication, inhalation techniques, exercise, nutritional aspects, smoking (cessation) and exacerbation management. During follow-up, patients in both groups had normal access to their physician. No attempts were made to change the frequency of scheduled visits. In addition to usual care, patients in the intervention group received an individualised written AP (see online supplement E1). Details on the development, validation and final content of the AP intervention are described elsewhere. ${ }^{18}$ The AP was individualised by the case manager together with the patient and provided a colour-coded overview of the patient's stable (green) and deteriorated symptom status (yellow: temporary or mild increase; orange: persistent or moderate increase; red: acute or threatening situation) related to individualised pharmaceutical and non-pharmaceutical treatment prescriptions. For individual patients it was optional for the case manager (in consultation with the attending physician) to provide self-treatment medication (course of corticosteroids and/or antibiotics). In contrast to the control group, patients in the AP group were encouraged to contact their case manager if they needed further information or wanted to ask a question. Two standardised reinforcement sessions were held by telephone at 1 and 4 months to evaluate the patient's understanding of and adherence to the AP and, when needed, additional information was provided (figure 1). Patients in the control group did not receive additional telephone sessions.

Baseline measurements were assessed 2 weeks before randomisation and exacerbation-related outcomes were recorded continuously throughout the study. ${ }^{18}$ Monthly telephone contacts were used to collect data on healthcare utilisation and subsequently verified or supplemented from medical records. At baseline and 6 months, health-related quality of life (St George's Respiratory Questionnaire, SGRQ), ${ }^{21}$ anxiety and depression (Hospital Anxiety and Depression Scale, $\mathrm{HADS}^{22}$ ) and exacerbation-related self-efficacy (recognition and prevention and action) were assessed. Details on the development and psychometric properties are described in online supplement E2.

All patients were instructed to record daily in a diary (see online supplement E3) whether symptoms were increased over their baseline condition. Patients received a 'what is normal' card which described their individual levels of major symptoms in a stable healthy state (see online supplement E4). Symptoms were classified as major (dyspnoea, sputum purulence, sputum volume) and minor (cough, wheeze, sore throat, fever and colds). Every 3 days the patients were asked to complete the $24 \mathrm{~h}$ version of the Clinical COPD Questionnaire (CCQ) to measure the longitudinal course of disease-related health status. ${ }^{18} 23$ All patients were contacted for monthly evaluation by telephone to assess healthcare utilisation and to evaluate proper use of the diary (figure 1). During these contacts the investigators (blind to allocation) attempted to fill the gaps with missing data. If the gaps were not more than 7 days and contacting the patient was not possible, a combination of last observation carried 
forward and next observation carried backward was used (see online supplement E5). ${ }^{24}$

A symptom-based exacerbation was defined by a clear increase in two symptoms for at least $48 \mathrm{~h}$, including at least one major symptom. This symptom-based definition ${ }^{25}$ has been validated against important outcome measures in COPD including the rate of lung function decline, ${ }^{3}$ airway inflammatory markers ${ }^{26}$ and quality of life. ${ }^{5}$ Exacerbation onset was defined as the first day on which the symptom criteria were met. Major symptoms were scored as normal (0 points), small increase (1 point) or clear increase ( 2 points). The minor symptoms were scored as 0 points if absent and 1 point if present. ${ }^{27}$ Adding all these scores resulted in a daily symptom count with a range of $0-11$ points. Recovery from an exacerbation was considered to have occurred when the 3 -day moving average of the symptom count returned to the mean symptom count on days 14 to 8 before the onset of the exacerbation. A subsequent exacerbation was defined as a new event only after at least five stable days. Exacerbations were classified according to Anthonisen et a $2^{25}$ based on the maximal number of major symptoms on one individual day during the episode (symptom intensity). To ensure rigorous and complete exacerbation counts, all diaries were reviewed by three blinded investigators who adjudicated events by consensus.

The primary endpoint was time to recovery of health status (CCO) in the event of an exacerbation. Three-day CCO assessments were recoded with respect to their longitudinal position from exacerbation onset (CCO unit -4 to +8$)$. Recovery was defined as the time when the CCO score had returned to the preexacerbation average (mean score of the third and fourth CCO assessments prior to onset). For each time point the health status (total, symptoms, mental state and functional state) was compared between the AP and control groups.

The length of an exacerbation was based on symptom recovery time. ${ }^{14} 28$ Other secondary outcomes were contact delay (time between exacerbation onset and exacerbation-related healthcare contact), health-related quality of life, anxiety and depression and exacerbation-related self-efficacy. Other exacerbation-related outcome measures were exacerbation rates, Anthonisen classification ${ }^{25}$ and percentage of exacerbations reported to a healthcare provider. The number of unscheduled physician visits, emergency room visits, courses of antibiotics and/or corticosteroids, hospitalisations and hospitalisation days were also compared between the two groups.

\section{STATISTICAL ANALYSIS}

We calculated that 73 exacerbations were required in both arms to have an $80 \%$ chance of detecting a 3-day difference (smallest detectable change) in health status recovery using a two-sided $\alpha=0.05{ }^{18}$

Between-group differences in CCO recovery were analysed with repeated measurement analysis using the SAS procedure PROC MIXED (mixed modelling). The covariance structure among repeated measures was modelled as 'compound symmetry'. Pre- and post-onset CCO scores were analysed as the dependent variable using treatment group as a key independent variable adjusted for the baseline CCO. Patient ID was included as an additional level to take into account multiple exacerbations per patient.

The length of the exacerbations and contact delay were analysed using a Cox proportional frailty model in R (V.2.11.1). Patient ID was included as a frailty term to adjust for multiple exacerbations per patient. ${ }^{29}$ Changes in SGRO, HADS, self-efficacy and healthcare contact outcome were analysed using analysis of covariance (ANCOVA) with baseline scores and centre as covariates included in the model. Weighted exacerbation rates were calculated per patient per year by dividing the total number of events by the total follow-up time and multiplying by 365.25 . CIs for the corresponding rate ratios were calculated using Poisson regression.

Figure 2 Patient enrolment scheme.

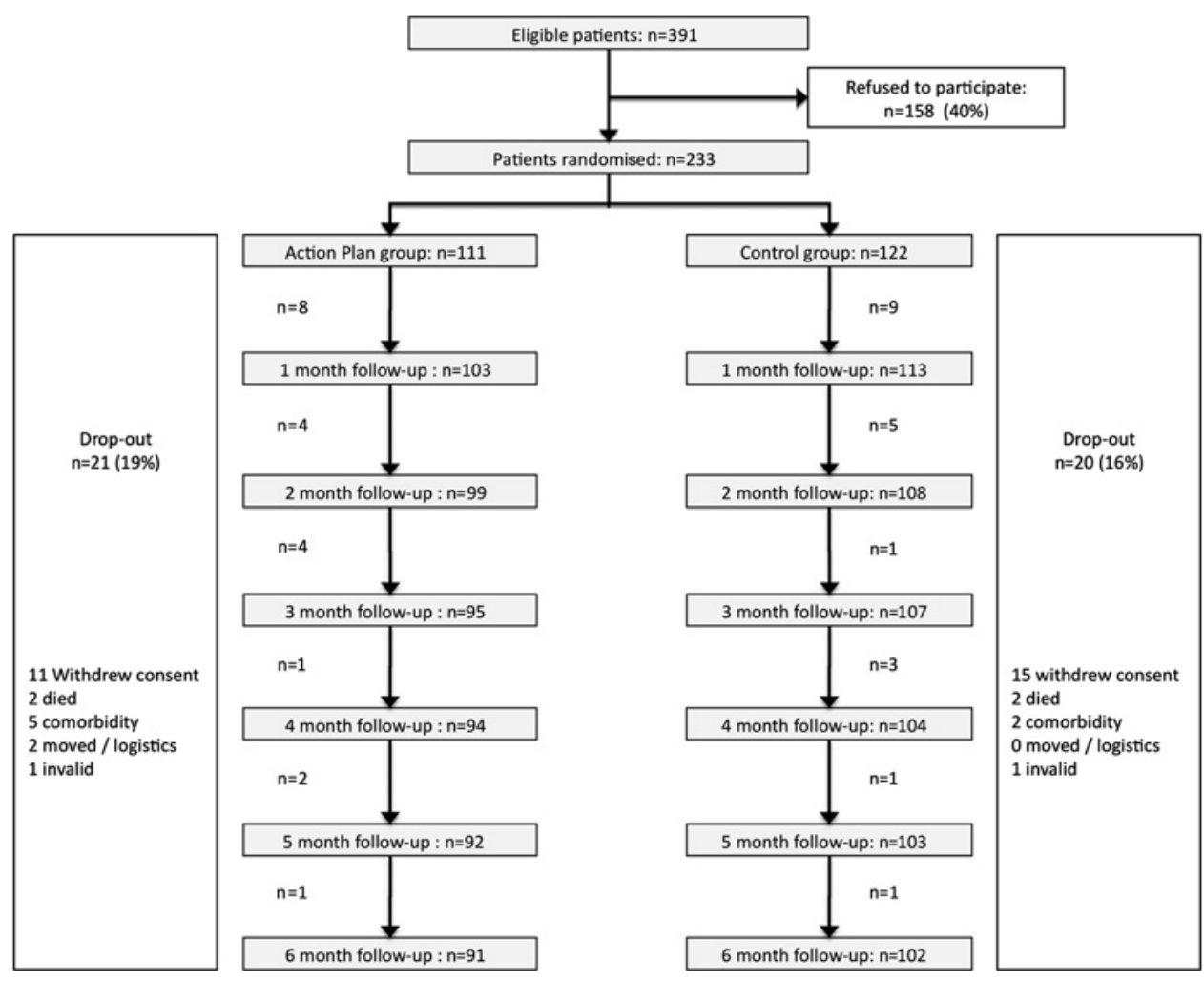


Table 1 Baseline characteristics of study population

\begin{tabular}{llll}
\hline & \multicolumn{2}{l}{ Randomised patients (n=233) } & \\
\cline { 2 - 3 } Variables & $\begin{array}{l}\text { Action plan } \\
\text { group (n=111) }\end{array}$ & $\begin{array}{l}\text { Control group } \\
(\mathbf{n}=122)\end{array}$ & $\begin{array}{l}\text { Lost to follow-up } \\
\text { (n=41) }\end{array}$ \\
\hline Gender, male & $65(59)$ & $69(57)$ & $27(51)$ \\
Age & $66.1 \pm 11.2$ & $65.1 \pm 10.0$ & $66.5 \pm 11.8$ \\
BMI & $26.1 \pm 5.5$ & $26.7 \pm 6.5$ & $24.1 \pm 3.5$ \\
Living alone & $27(23)$ & $22(18)$ & $11(27)$ \\
Educational level & & & \\
$\quad$ Lower secondary or less & $69(62)$ & $83(68)$ & $29(70)$ \\
$\quad$ Higher secondary & $29(26)$ & $31(25)$ & $9(23)$ \\
$\quad$ College/university & $13(12)$ & $8(7)$ & $3(7)$ \\
Current smoking & $31(28)$ & $37(30)$ & $12(29)$ \\
GOLD stage & & & \\
$\quad$ I & $14(13)$ & $13(11)$ & $2(6)^{*}$ \\
II & $55(50)$ & $58(47)$ & $18(43)$ \\
III & $30(27)$ & $38(31)$ & $11(27)$ \\
$\quad$ IV & $11(10)$ & $12(10)$ & $10(24)$ \\
FEV & $1.55 \pm 0.60$ & $1.59 \pm 0.71$ & $1.35 \pm 0.70 \dagger$ \\
FEV ${ }_{1} \%$ predicted & $56.7 \pm 20.3$ & $56.5 \pm 20.6$ & $50.9 \pm 23.7$ \\
FVC & $3.03 \pm 0.79$ & $3.17 \pm 0.91$ & $2.86 \pm 0.94$ \\
Recruited from & & & \\
$\quad$ GP & $18(16)$ & $17(14)$ & $2(5)^{*}$ \\
Outpatient clinic & $93(84)$ & $105(86)$ & $39(95)$ \\
\hline
\end{tabular}

Data are presented as $\mathrm{n}$, mean \pm SD or $\mathrm{n}(\%)$.

${ }^{*} \mathrm{p}<0.05$ ( $\chi^{2}$ test).

$t p<0.05$ (Student $t$ test): difference between patients lost to follow-up compared with patients with 6 months of follow-up.

BMI, body mass index; $\mathrm{FEV}_{1}$, forced expiratory volume in $1 \mathrm{~s}$; FVC, forced vital capacity; GOLD, Global initiative of Obstructive Lung Disease.

\section{RESULTS}

Patient recruitment started in December 2008 and ended in April 2010. Of the eligible 391 patients, 233 were randomly assigned to either the AP $(n=111)$ or control group $(n=122)$. Monthly discontinuation rates and reasons for withdrawal were comparable in both study arms (figure 2). Exacerbation-related outcomes were assessed in the 216 patients who provided at least 1 month of diary data. Table 1 shows the baseline charac- teristics of the two study groups. Subjects lost to follow-up had more severe airflow limitation and were more frequently recruited from an outpatient clinic $(p<0.05)$. At baseline, 12 patients in the AP group and 14 patients in the control group had access to a course of corticosteroids and/or antibiotics. After the first consultation, four additional patients in the AP group received direct access to self-treatment medication.

Compliance and completeness of diary recording was high; participants completed a total of 36.096 diary-days. After monthly recall, 982 (2.7\%) diary-days were imputed using the predefined methods. Imputation was not possible for 176 diary-days (gaps $>7$ days). During the study period 264 symptom-based exacerbations occurred, 128 in the AP group and 136 in the control group. In both groups approximately $50 \%$ of patients remained exacerbation-free while $30 \%$ experienced $\geq 1$ exacerbation. Weighted exacerbation rates were similar for the two groups (table 2).

Figure 3 shows Cox-adjusted probabilities of health status and symptom recovery in the event of an exacerbation. At 24 days post-onset, $25(20 \%)$ exacerbations in the AP group and $34(25 \%)$ in the control group were censored due to non-recovery. Health status recovery was shorter and almost significant in the AP group (HR 1.58, 95\% CI 0.96 to 2.60). Mean health status recovery time was shorter in the AP group than in the control group ( $8.7 \pm 6.5$ days vs $10.9 \pm 8.1$ days), with a non-statistically significant mean difference of -2.2 days ( $95 \% \mathrm{CI}-5.7$ to 1.4$)$. A similar pattern in favour of the AP group was seen in the analysis of symptom recovery time, with a slightly lower HR of 1.30 (95\% CI 0.92 to 1.84 ). The mean symptom recovery time was significantly shorter in the AP group (-3.68 days, 95\% CI -7.32 to -0.04$)$.

Repeated measures analysis showed that, in the prodromal period, both groups had a similar pattern of gradually reducing health status followed by an acute decline at onset (figure 4). In control patients the increase in CCQ scores started earlier than in the AP group and the absolute increase was higher. Mean differences in CCO scores over time were analysed for the postonset period including two prodromal assessments and the

Table 2 Exacerbation-related outcomes according to intervention group

\begin{tabular}{|c|c|c|c|c|}
\hline Outcome & $\begin{array}{l}\text { Action plan } \\
\text { group }(n=103 \text { ) }\end{array}$ & $\begin{array}{l}\text { Control group } \\
(n=113)\end{array}$ & $\begin{array}{l}\text { Treatment difference } \\
(95 \% \mathrm{CI})\end{array}$ & p Value \\
\hline Total patient-years & 46.65 & 52.24 & & \\
\hline Mean follow-up per patient (years) & $0.45 \pm 0.11$ & $0.46 \pm 0.09$ & $-0.01(-0.04$ to 0.02$)$ & $0.50^{*}$ \\
\hline Number of exacerbations & 128 & 136 & & \\
\hline Weighted exacerbation rate (patient-year) & 2.80 & 2.60 & $1.07(0.76$ to 1.25$)$ & $0.73 \dagger$ \\
\hline \multicolumn{5}{|l|}{ Number of patients with } \\
\hline 0 exacerbation & $48(47)$ & $57(50)$ & & $0.77 \neq$ \\
\hline 1 exacerbation & $24(23)$ & $22(20)$ & & \\
\hline$>1$ exacerbations & $31(30)$ & $34(30)$ & & \\
\hline \multicolumn{5}{|l|}{ Exacerbation days for } \\
\hline All patients & $19.4 \pm 26.8$ & $21.8 \pm 32.3$ & $-2.4(-10.4$ to 5.6$)$ & $0.56^{*}$ \\
\hline Patients with $\geq 1$ exacerbation & $35.1 \pm 27.6$ & $44.1 \pm 33.6$ & $-9.0(-20.5$ to 2.6$)$ & $0.13^{*}$ \\
\hline \multicolumn{5}{|l|}{ Anthonisen classification§ } \\
\hline 3 major symptoms & $28(22)$ & $41(30)$ & & $0.03 \neq$ \\
\hline 2 major symptoms & $33(26)$ & $48(35)$ & & \\
\hline 1 major $+\geq 1$ minor symptom & $67(52)$ & $47(35)$ & & \\
\hline Symptom count (points)§ & $77.2 \pm 65.0$ & $85.1 \pm 90.1$ & $-8.0(-12.8$ to 28.9$)$ & $0.45^{*}$ \\
\hline Reported exacerbations $\S$ & $37(29)$ & $46(34)$ & & $0.55 \neq$ \\
\hline Contact delay (days)§ & $4.5 \pm 5.9$ & $7.5 \pm 8.8$ & $-2.9(-3.5$ to 2.4$)$ & $<0.001^{*}$ \\
\hline
\end{tabular}


Figure 3 Cox-adjusted survival curves of time to $(A)$ health status recovery and (B) symptom recovery for the action plan and control groups. Both Cox survival curves are adjusted for multiple events (including patient ID as a frailty term in the model). (A) Percentage of patients recovered per time point in terms of health status (Clinical COPD Questionnaire, CCO) recovery. (B) Percentage of patients recovered in terms of symptom (moving symptom count) recovery.
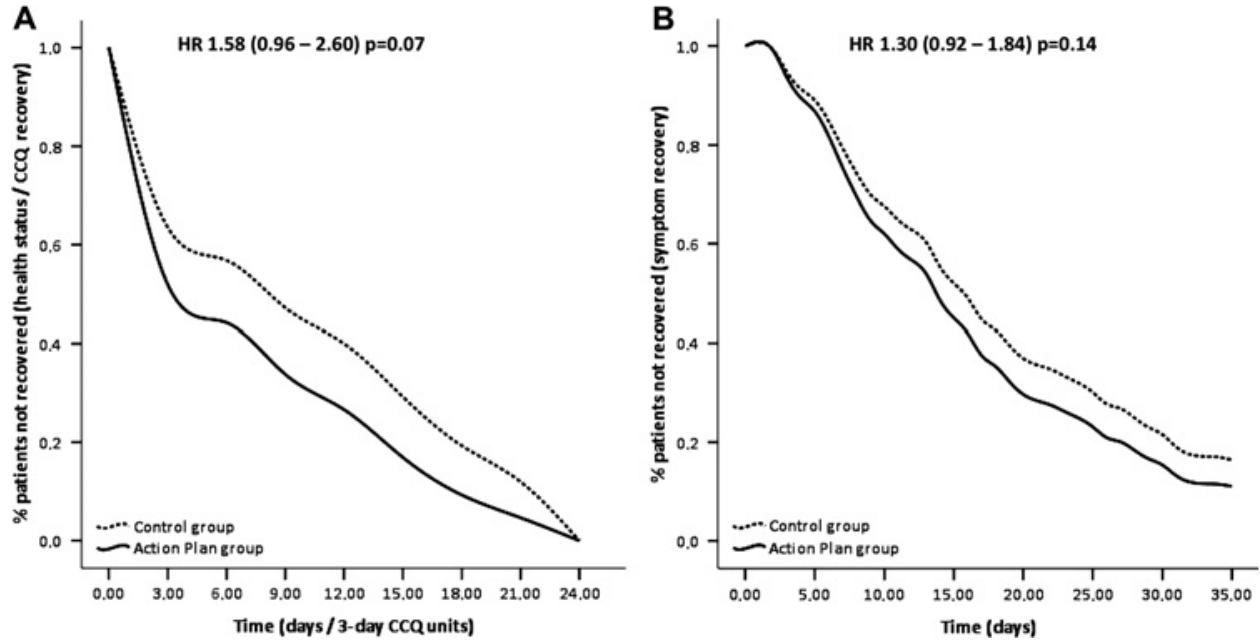

post-onset period (figure 4). The mean difference in post-onset course of the CCQ symptom domain was statistically significant $(-0.33,95 \%$ CI -0.68 to -0.01$)$. Single time point comparisons showed that, in the first 3 days after onset, the mean CCO total, symptom and functional scores were significantly lower in the AP group. For the CCQ total score the between-group difference at day 3 was more than the minimal clinical important difference of 0.4 points. ${ }^{30}$ The difference in the mean CCQ symptom score continued to be statistically significant up to 6 days post- onset, after which both the CCQ total score and the symptom and functional domain scores remained lower in the AP group but the speed of recovery was identical, as indicated by parallel slopes and overlapping CIs. Change in health status between baseline and the first measurement post-onset was associated with health status recovery time $(r=0.68, p<0.001)$, indicating that exacerbations have a high impact on health status with a longer time to recovery. Post-hoc analysis did not show any seasonal differences in exacerbation-related outcomes.
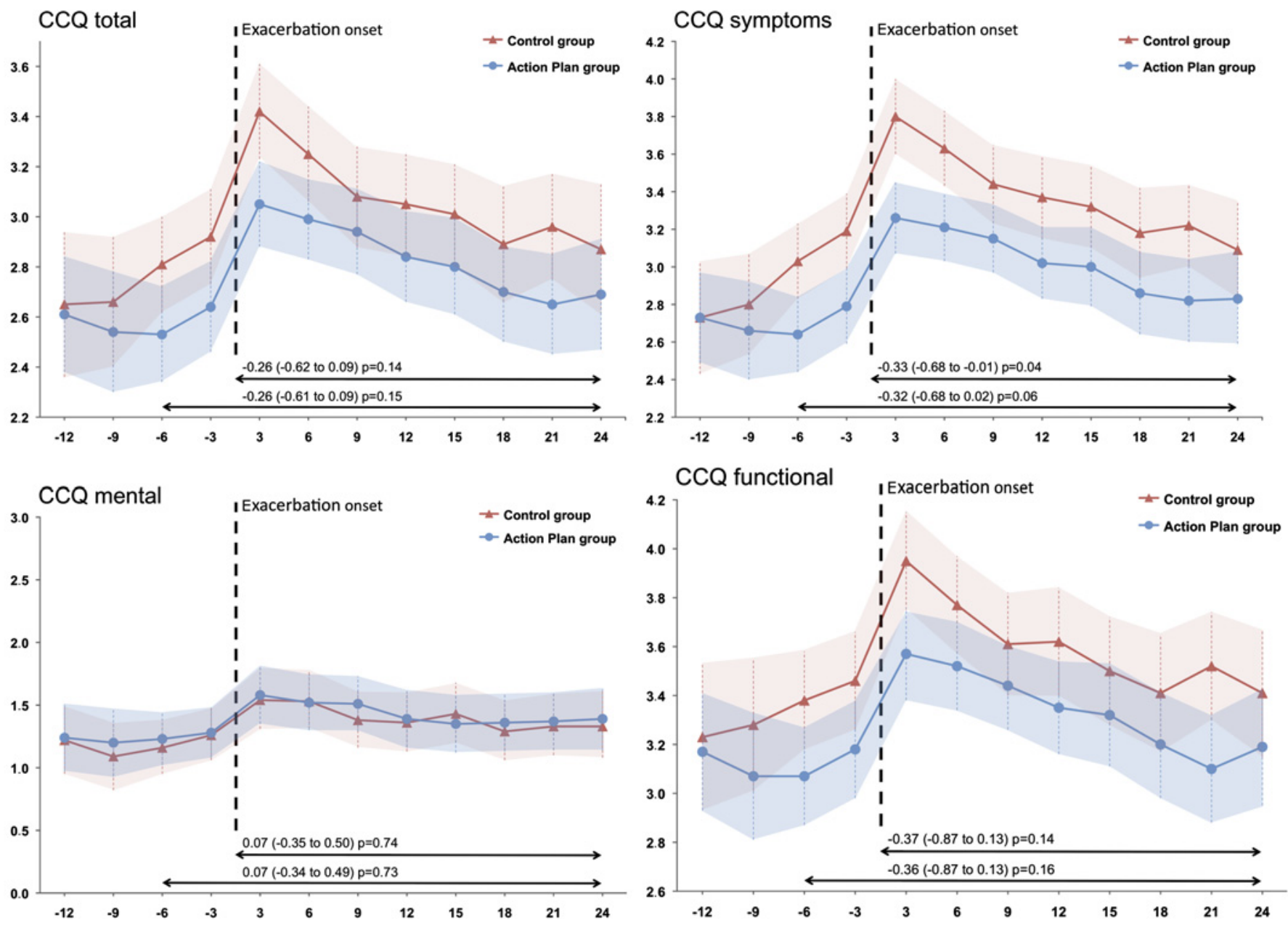

Figure 4 Health status recovery in the event of an exacerbation. CCO, Clinical COPD Questionnaire. 
Table 3 Changes in health-related quality of life, dyspnoea, depression, anxiety and self-efficacy according to intervention group

\begin{tabular}{|c|c|c|c|c|c|}
\hline \multirow[b]{2}{*}{ Outcome } & \multicolumn{2}{|c|}{ Mean (SE) change from baseline } & \multirow[b]{2}{*}{$\begin{array}{l}\text { Mean ( } 95 \% \text { CI) difference } \\
\text { in change from baseline }\end{array}$} & \multirow{2}{*}{$\begin{array}{l}\text { Mean }(95 \% \mathrm{CI}) \text { adjusted } \\
\text { difference in change } \\
\text { from baseline* }\end{array}$} & \multirow[b]{2}{*}{ p Value } \\
\hline & $\begin{array}{l}\text { Action plan } \\
\text { group }(n=86)\end{array}$ & $\begin{array}{l}\text { Control group } \\
(\mathrm{n}=97)\end{array}$ & & & \\
\hline SGRO Total & $-0.4(1.1)$ & $1.2(1.3)$ & $-0.8(-4.1$ to 2.4$)$ & $-1.3(-4.4$ to 1.9$)$ & 0.42 \\
\hline SGRO Symptom & $-3.6(2.3)$ & $-0.6(2.1)$ & $-3.1(-9.1$ to 3.0$)$ & $-3.4(-9.0$ to 2.2$)$ & 0.23 \\
\hline SGRQ Impact & $-0.1(1.4)$ & $0.8(1.0)$ & $-0.8(-4.1$ to 2.4$)$ & $-1.3(-4.4$ to 1.9$)$ & 0.42 \\
\hline HADS depression & $-0.2(0.3)$ & $-0.3(0.3)$ & $0.1(-0.7$ to 1.0$)$ & $0.0(-0.8$ to 0.8$)$ & 0.95 \\
\hline Self-efficacy prevention / action & $-0.7(0.1)$ & $0.2(0.1)$ & $-1.0(-1.3$ to -0.7$)$ & $-0.7(-1.0$ to -0.5$)$ & $<0.001$ \\
\hline
\end{tabular}

*Difference in change from baseline adjusted for the baseline value of the parameter and centre; corresponding 95\% Cls and $\mathrm{p}$ values are calculated using ANCOVA.

HADS, Hospital Anxiety and Depression Scale; SGRO, St George's Respiratory Questionnaire.

Exacerbations in the AP group on average had lower symptom intensity according to the Anthonisen classification $(p=0.03$, table 2). No differences were observed in the proportion of exacerbations reported to a healthcare provider (29\% and 34\%). When an exacerbation was reported, patients in the AP group reported on average 2.9 (95\% CI 2.4 to 3.5 ) days faster than those in the control group $(p<0.001)$. Post-hoc analysis showed that type I exacerbations tended to be reported more frequently in the AP group (67\% vs $43 \%$ ).

No statistical differences were observed in the mean change in SGRQ and HADS scores (table 3). At 6 months, $41.5 \%$ of patients in the AP group had exceeded the threshold of a 4-point improvement in the SGRQ total score compared with $31.6 \%$ in the control group (risk difference 10.5\%). The change in exacerbation-related self-efficacy was significantly higher in the AP group $(p<0.001)$. No statistical differences were observed in the mean change in unscheduled physician visits, inhalation medication, courses of antibiotics/steroids, hospital admissions and emergency room visits (table 4).

\section{DISCUSSION}

This study shows that individualised written APs including ongoing support of a case manager decrease the impact of exacerbations on health status, decrease symptom intensity of exacerbations and tend to accelerate recovery of exacerbations in terms of health status and symptoms. A written AP per se did not affect the exacerbation rate or the overall utilisation of healthcare resources during 6 months of follow-up. In contrast to our hypothesis, no differences were observed in the proportion of exacerbations reported to a healthcare provider.

Although exacerbation rates were similar in the two groups, the results indicate a higher likelihood for complete remission of health status and symptoms after exacerbation onset in the AP group. Full symptom recovery was reached an average of 3.7 days earlier in the AP group, which was determined by a validated rule for exacerbation recovery. Our findings are consistent with other studies showing that the use of an AP does not influence the exacerbation rate but may facilitate their recovery. ${ }^{27}{ }^{31}$ Since rapid symptom relief is a desired outcome from a patient's perspective, ${ }^{32}$ this outcome can be considered as highly clinically relevant. It needs to be emphasised that comparison with other studies is not entirely relevant since we did not primarily focus on self-initiation of courses of steroids and/or antibiotics in the event of an exacerbation.

A second important finding of our study is that exacerbations in the AP group were perceived as substantially milder by patients. In the first three post-onset days the mean betweengroup difference in the CCO total score was more than the minimal clinically important difference, indicating that patients felt less unwell during these events. We also found that a substantial amount of the difference in health status impact after onset was already observed in the first six prodromal days. Taken into account the similar scores at baseline, this response pattern might be explained by a more adequate response to the early warning signs of an exacerbation. Remarkably, although the AP partly aims at early contact with a healthcare provider, no differences were seen in the number of reported

Table 4 Healthcare utilisation according to intervention group

\begin{tabular}{|c|c|c|c|c|c|c|c|}
\hline \multirow[b]{2}{*}{ Outcome } & \multicolumn{2}{|c|}{ Action plan group* $(n=109)$} & \multicolumn{2}{|c|}{ Control group* $(n=118)$} & \multirow{2}{*}{$\begin{array}{l}\text { Mean difference in } \\
\text { change from baseline } \\
(95 \% \mathrm{CI})\end{array}$} & \multirow{2}{*}{$\begin{array}{l}\text { Adjusted mean difference } \\
\text { in change from baseline } \dagger \\
(95 \% \mathrm{Cl})\end{array}$} & \multirow[b]{2}{*}{ p Value } \\
\hline & $\begin{array}{l}\text { Baseline } \\
\text { (6 months) }\end{array}$ & $\begin{array}{l}\text { Study period } \\
\text { (6 months) }\end{array}$ & $\begin{array}{l}\text { Baseline } \\
\text { (6 months) }\end{array}$ & $\begin{array}{l}\text { Study period } \\
\text { ( } 6 \text { months) }\end{array}$ & & & \\
\hline Unscheduled physician visits & $1.2 \pm 1.7$ & $0.9 \pm 1.5$ & $1.1 \pm 1.5$ & $0.9 \pm 1.2$ & $0.12(-0.38$ to 0.63$)$ & $-0.12(-0.38$ to 0.41$)$ & 0.93 \\
\hline Courses of antibiotics & $1.0 \pm 1.6$ & $0.5 \pm 1.0$ & $1.0 \pm 1.4$ & $0.5 \pm 1.0$ & $0.02(-0.40$ to 0.44$)$ & $0.03(-0.30$ to 0.25$)$ & 0.86 \\
\hline Courses of corticosteroids & $0.5 \pm 0.9$ & $0.5 \pm 0.9$ & $0.5 \pm 0.9$ & $0.5 \pm 0.9$ & $-0.01(-0.31$ to 0.30$)$ & $-0.00(-0.25$ to -0.24$)$ & 0.98 \\
\hline Physician-initiated increase in inhalation intake & $0.3 \pm 0.6$ & $0.2 \pm 0.4$ & $0.4 \pm 0.8$ & $0.3 \pm 0.6$ & $0.01(-0.24$ to 0.25$)$ & $0.02(-0.31$ to 0.24$)$ & 0.90 \\
\hline $\begin{array}{l}\text { Emergency department visits for COPD } \\
\text { exacerbation }\end{array}$ & $0.2 \pm 0.5$ & $0.1 \pm 0.3$ & $0.1 \pm 0.4$ & $0.1 \pm 0.4$ & $0.09(-0.04$ to 0.22$)$ & $-0.04(-0.05$ to 0.13$)$ & 0.41 \\
\hline Hospitalisation for COPD exacerbation & $0.2 \pm 0.4$ & $0.1 \pm 0.3$ & $0.2 \pm 0.5$ & $0.1 \pm 0.3$ & $0.02(-0.11$ to 0.15$)$ & $-0.00(-0.07$ to 0.08$)$ & 0.91 \\
\hline \multicolumn{8}{|l|}{ Number of patients with } \\
\hline No hospital admission & $87(80)$ & $102(94)$ & $97(82)$ & $109(93)$ & & & 0.72 \\
\hline 1 hospital admission & $21(19)$ & $7(6)$ & $18(15)$ & $9(8)$ & & & \\
\hline$>1$ hospital admission & $1(1)$ & $0(0)$ & $3(3)$ & $0(0)$ & & & \\
\hline Hospitalisation days for COPD exacerbation $\ddagger$ & $12.3 \pm 8.3$ & $6.6 \pm 2.8$ & $10.6 \pm 5.2$ & $11.9 \pm 9.8$ & $-5.36(-12.15$ to 1.43$)$ & $-4.15(-16.68$ to 1.38$)$ & 0.09 \\
\hline
\end{tabular}

*Unless otherwise indicated, data are mean \pm SD or $\mathrm{n}(\%)$.

†Difference in change from baseline adjusted for the baseline value of the parameter and centre; corresponding $95 \%$ Cls and $p$ values are calculated using ANCOVA.

$\ddagger$ Number of days for patients with at least one exacerbation-related hospital admission.

COPD, chronic obstructive pulmonary disease. 
exacerbations. However, reporting patterns showed that Anthonisen type I exacerbations tended to be reported more frequently in the AP group. Furthermore, if exacerbations were reported, patients with an AP contacted their healthcare provider an average of 2.9 days earlier than control patients.

The fact that patients with an AP did not contact their physician more often for all exacerbations could be partly explained by milder events occurring in this group. This corresponds with the findings from a Canadian cohort showing that the number of symptoms at onset is associated with reporting. ${ }^{10}$ Another explanation might be that exacerbation-related selfefficacy significantly increased in the AP group, both in the recognition and the prevention/action domain. Although this questionnaire requires further validation, these findings indicate that an AP leads to increased confidence in being able to manage periods of worsening health status. ${ }^{17} 33$ Increased self-efficacy is important since it is considered to be a strong predictor of behaviour change. ${ }^{34} 35$

Our findings are consistent with a meta-analysis indicating that isolated AP use results in an increased ability to recognise and react appropriately to an exacerbation by individuals, but fails to reduce utilisation of healthcare resources or to improve health-related quality of life. ${ }^{17}$ In contrast, a recent randomised trial reported self-treatment (using an AP) to be cost-effective due to a significant decrease in healthcare contacts and lower probability of hospital admissions. ${ }^{27}$ We hypothesised that APs primarily have the potential to help patients distinguish periods of symptom deterioration and subsequently support taking prompt and adequate action measures to prevent escalation of exacerbations. Our study was therefore not primarily designed to be a clear assessment of the effects on utilisation of healthcare resources. 18

Our study has a number of strengths. First, inclusion of patients from scheduled visits to a respiratory or general physician resulted in a representative sample of patients with COPD with a wide range of exacerbation frequencies and severity. Second, a pragmatic study design using a modified informed consent procedure enabled us to obtain an unbiased and generalisable assessment of the isolated effectiveness of an AP. ${ }^{18}$ Third, the exacerbations were meticulously assessed using diary cards, and adequate methods to check the validity and completeness (monthly recall and imputation) enabled us to capture a near complete longitudinal picture of all exacerbations and their characteristics. Fourth, this is the first study to asses prospectively and comprehensively the impact of exacerbations on health status. Examining the $\mathrm{CCO}$ every 3 days made it possible to report a detailed and consistent effect of the AP across different domains over time, adding credibility to the results. Fifth, state-of-the-art analyses enabled evaluation of all exacerbations including adjustment for multiple events within a single patient.

Some potential limitations of our study should also be discussed. We did not ask patients to record self-management strategies and action measures during periods of increasing symptoms. This could have influenced the behaviour of patients in both groups and subsequently affected the internal validity of the study. A major disadvantage was that it hampered a posteriori evaluation of associations between certain self-management behaviour and the longitudinal course of symptoms and health status. Although we believe our decision is justified in order to prevent unbiased results, we lack useful data on the mechanisms of symptom recognition and interpretation. Furthermore, we did not obtain the a priori number of exacerbations. To optimise the external validity we deliberately chose not to select patients according to the likelihood of exacerbations but, instead, targeted the general population of patients with COPD. This resulted in a substantial number of patients without an exacerbation, which was slightly higher than anticipated in the original sample size calculation. We calculated that 73 exacerbations were needed but only 55 patients in the AP group and 56 in the AP group had at least one exacerbation. However, although this was not intended in the original sample size calculation, statistical power was preserved by advanced analysis enabling evaluation of all exacerbations including adjustment for multiple events within a single patient.

This study has shown that an individualised AP, including ongoing support by a case manager, is able to decrease the impact of exacerbations on health status and tends to accelerate recovery. Given the detrimental effect of exacerbations on health status, this relatively simple and straightforward intervention can be regarded as relevant both for patients and providers. The effect on exacerbation-related outcome and self-efficacy, without an increase in utilisation of healthcare resources, suggests that APs are a key component of self-management programmes in patients with COPD. More research is needed to assess selfmanagement approaches to increasing patients' ability to recognise and react appropriately to exacerbations. Properly designed studies are also needed to show the effects of simplified self-management approaches, including a written AP, on healthcare utilisation.

Acknowledgements The authors are grateful to the patients and their families and acknowledge the trial investigators, respiratory physicians, family physicians, practice assistants and respiratory nurses for their dedication to the study.

Competing interests None.

Patient consent Obtained.

Ethics approval This study was approved by Utrecht Medical Ethical Committee.

Contributors JCAT led the development of the study conceptualisation, design, refining of protocol and write up for publication. EMM contributed to the development of the study design, statistical issues and protocol publication. JB and TT contributed expert respiratory input into study conceptualisation and refining of outcome measures, statistical issues and substantial contribution to writing up of the protocol for publication. AJPS, TJMV and J-WJL contributed to study and intervention development and to protocol publication.

Provenance and peer review Not commissioned; externally peer reviewed.

\section{REFERENCES}

1. Lopez AD, Mathers CD, Ezzati M, et al. Global and regional burden of disease and risk factors, 2001: systematic analysis of population health data. Lancet 2006;367:1747-57

2. Kanner RE, Anthonisen NR, Connett JE. Lower respiratory illnesses promote FEV(1) decline in current smokers but not ex-smokers with mild chronic obstructive pulmonary disease: results from the lung health study. Am J Respir Crit Care Med 2001;164:358-64.

3. Donaldson GC, Seemungal TA, Bhowmik A, et al. Relationship between exacerbation frequency and lung function decline in chronic obstructive pulmonary disease. Thorax 2002; 57:847-52.

4. Cote CG, Dordelly LJ, Celli BR. Impact of COPD exacerbations on patient-centered outcomes. Chest 2007;131:696-704.

5. Seemungal TA, Donaldson GC, Paul EA, et al. Effect of exacerbation on quality of life in patients with chronic obstructive pulmonary disease. Am J Respir Crit Care Med 1998:157:1418-22

6. Miravitlles M, Ferrer M, Pont A, et al. Effect of exacerbations on quality of life in patients with chronic obstructive pulmonary disease: a 2 year follow up study. Thorax 2004;59:387-95.

7. Soler-Cataluna JJ, Martinez-Garcia MA, Roman SP, et al. Severe acute exacerbations and mortality in patients with chronic obstructive pulmonary disease. Thorax 2005:60:925-31.

8. Connors AF Jr, Dawson NV, Thomas C, et al. Outcomes following acute exacerbation of severe chronic obstructive lung disease. The SUPPORT investigators (Study to Understand Prognoses and Preferences for Outcomes and Risks of Treatments). Am J Respir Crit Care Med 1996;154:959-67.

9. Kessler R, Stahl E, Vogelmeier C, et al. Patient understanding, detection, and experience of COPD exacerbations: an observational, interview-based study. Chest 2006;130:133-42. 
10. Langsetmo L, Platt RW, Ernst P, et al. Underreporting exacerbation of chronic obstructive pulmonary disease in a longitudinal cohort. Am J Respir Crit Care Med 2008;177:396-401.

11. Seemungal TA, Donaldson GC, Bhowmik A, et al. Time course and recovery of exacerbations in patients with chronic obstructive pulmonary disease. Am J Respir Crit Care Med 2000:161:1608-13.

12. Vijayasaratha $\mathbf{K}$, Stockley RA. Reported and unreported exacerbations of COPD: analysis by diary cards. Chest 2008;133:34-41.

13. $\mathbf{X u} \mathbf{W}$, Collet JP. Shapiro $\mathrm{S}$, et al. Negative impacts of unreported COPD exacerbations on health-related quality of life at one year. Eur Respir $J$ 2010;35:1022-30.

14. Wilkinson TM, Donaldson GC, Hurst JR, et al. Early therapy improves outcomes of exacerbations of chronic obstructive pulmonary disease. Am J Respir Crit Care Med 2004;169:1298-303.

15. Bourbeau J, Julien M, Maltais F, et al. Reduction of hospital utilization in patients with chronic obstructive pulmonary disease: a disease-specific self-management intervention. Arch Intern Med 2003:163:585-91.

16. Effing T, Monninkhof EM, van der Valk $\mathrm{P}$, et al. Self-management education for patients with chronic obstructive pulmonary disease. Cochrane Database Syst Rev 2007:(4):CD002990.

17. Walters JA, Turnock AC, Walters $\mathrm{EH}$, et al. Action plans with limited patient education only for exacerbations of chronic obstructive pulmonary disease. Cochrane Database Syst Rev 2010;(5):CD005074.

18. Trappenburg JC, Koevoets $\mathrm{L}$, de Weert-van Oene GH, et al. Action Plan to enhance self-management and early detection of exacerbations in COPD patients; a multicenter RCT. BMC Pulm Med 2009;9:52

19. Boter H, van Delden JJ, de Haan RJ, et al. Modified informed consent procedure: consent to postponed information. BMJ 2003;327:284-5.

20. Rabe KF, Hurd S, Anzueto A, et al. Global strategy for the diagnosis, management and prevention of COPD - 2006 update. Am J Respir Crit Care Med 2007:176:532-55

21. Jones PW, Quirk FH, Baveystock CM. The St George's Respiratory Questionnaire Respir Med 1991;85(Suppl B):25-31.
22. Zigmond AS, Snaith RP. The hospital anxiety and depression scale. Acta Psychiatr Scand 1983;67:361-70.

23. van der Molen T, Willemse BW, Schokker S, et al. Development, validity and responsiveness of the Clinical COPD Ouestionnaire. Health Oual Life Outcomes 2003;:13.

24. Engels JM, Diehr P. Imputation of missing longitudinal data: a comparison of methods. J Clin Epidemiol 2003;56:968-76.

25. Anthonisen NR, Manfreda J, Warren CP, et al. Antibiotic therapy in exacerbations of chronic obstructive pulmonary disease. Ann Intern Med 1987:106:196-204.

26. Bhowmik A, Seemungal TA, Sapsford RJ, et al. Relation of sputum inflammatory markers to symptoms and lung function changes in COPD exacerbations. Thorax 2000;55:114-20.

27. Effing TW, Kerstjens HA, Zielhuis GA, et al. The (cost)-effectiveness of selftreatment of exacerbations on the severity of exacerbations in COPD patients: the COPE-II study. Thorax 2009:64:956-62.

28. Hurst JR, Donaldson GC, Quint JK, et al. Temporal clustering of exacerbations in chronic obstructive pulmonary disease. Am J Respir Crit Care Med 2009;179:369-74.

29. Box-Steffensmeier JM, De BS. Repeated events survival models: the conditional frailty model. Stat Med 2006;25:3518-33.

30. Kocks JW, Tuinenga MG, Uil SM, et al. Health status measurement in COPD: the minimal clinically important difference of the clinical COPD questionnaire. Respir Res 2006; 7:62.

31. Bischoff EW, Hamd DH, Sedeno $M$, et al. Effects of written action plan adherence on COPD exacerbation recovery. Thorax 2011;66:26-31.

32. Miravitlles $\mathbf{M}$, Anzueto A, Legnani D, et al. Patient's perception of exacerbations of COPD-the PERCEIVE study. Respir Med 2007:101:453-60.

33. Wood-Baker R, McGlone S, Venn A, et al. Written action plans in chronic obstructive pulmonary disease increase appropriate treatment for acute exacerbations. Respirology 2006;11:619-26.

34. Bandura A. The assessment and predictive generality of self-percepts of efficacy. $J$ Behav Ther Exp Psychiatry 1982:13:195-9.

35. Bourbeau J, van der Palen J. Promoting effective self-management programmes to improve COPD. Eur Respir J 2009;33:461-3.

\section{Journal club}

\section{VX-770, a CFTR potentiator, may have a potential clinical benefit in a subgroup of people with cystic fibrosis}

Cystic fibrosis (CF) is caused by mutations in the gene encoding the CFTR (CF transmembrane conductance regulator) protein, an epithelial ion channel. Some mutations, of which the G551D mutation is the most common (occurring in approximately $5 \%$ of people with CF), permit the defective CFTR protein to reach the epithelial cell surface. VX-770, a CFTR potentiator, has been shown to increase the activity of defective cell-surface CFTR in vitro. In this small, randomised, double-blinded study, the effects of oral VX-770 in adults with CF and at least one G551D-CFTR allele were evaluated. CFTR ion-channel function was assessed by measuring nasal potential difference and sweat chloride concentration.

At day 28, in the VX-770150 mg group ( $\mathrm{n}=8$ ), changes in sweat chloride concentration from baseline were significant for within-subject comparisons and versus placebo $(n=4)$. Significant within-subject changes from baseline in nasal potential difference and $\mathrm{FEV}_{1}$ were demonstrated. However, both these changes lacked significance when compared with the placebo group. No subject withdrew from the study.

This study demonstrated significant within-subject differences in CFTR and lung function. However, significant improvements were not demonstrated in comparisons between the treatment and placebo groups. The results of this study should be interpreted with caution in view of the small size of the groups involved. Further research into the potential clinical benefit of CFTR potentiators is required.

- Accurso FJ, Rowe SM, Clancy JP, et al. Effect of VX-770 in persons with cystic fibrosis and the G551D-CFTR mutation. N Engl J Med 2010:363:1991-2003.

\section{Sneh Shah}

Correspondence to Sneh Shah, ACCS CT1, Croydon University Hospital, 530 London Road, Croydon CR7 7YE, UK; sneh.shah@doctors.net.uk 